Ramadhan, et al/Jurnal Ekonomi Syariah Teori dan Terapan Vol. 6 No. 8 Agustus 2019: 1637-1643; HUBUNGAN DANA PENANGGULANGAN KEMISKINAN PEMERINTAH DAN ZISWAF TERHADAP JUMLAH PENDUDUK MISKIN

\title{
HUBUNGAN DANA PENANGGULANGAN KEMISKINAN PEMERINTAH DAN ZISWAF TERHADAP JUMLAH PENDUDUK MISKIN'
}

\author{
M. Muammar Ramadhan \\ Departemen Ekonomi Syariah - Fakultas Ekonomi dan Bisnis - Universitas Airlangga \\ Email: ramaramadhan9902@gmail.com \\ Eko Fajar Cahyono \\ Departemen Ekonomi Syariah - Fakultas Ekonomi dan Bisnis - Universitas Airlangga \\ Email: fajars2ie@gmail.com
}

\begin{abstract}
:
The purpose of this study is to analyze the relationship of poverty reduction fund and ZISWAF to the number of poor people in Indonesia. This study uses quantitative approach. The data used are secondary data from official website baznas, kemenkeu and bps. Data analysis techniques used to answer the research problem and test the research hypothesis using Spearman correlation.Based on the results of the analysis known poverty alleviation funds have a negative relationship to the number of poor people in Indonesia, while ZISWAF have a non-negative relationship to the number of poor educators in Indonesia.
\end{abstract}

Keywords: Poverty Reduction Fund, ZISWAF, Poverty.

\section{PENDAHULUAN}

Indonesia berkewajiban untuk mengurangi dan menanggulangi angka kemiskinan. Seperti yang dituliskan pada amanat konstitusi pasal 34 ayat 1 UUD 1945 yang menyebutkan bahwa fakir, miskin, dan anak terlantar dipelihara oleh negara. Dapat disimpulkan bahwa negara wajib untuk memberikan kebutuhan dasar yang cukup untuk warga negara yang masuk dalam kelompok fakir, miskin dan anak terlantar.

Kemiskinan merupakan salah satu penyakit perekonomian yang ada pada setiap negara. Permasalahan kemiskinan merupakan masalah yang kompleks dan multi dimensional, diantaranya adalah menyebabkan kesengsaraan, menghilangkan martabat manusia, membebani semua negara, mengurangi kualitas sumber daya manusia (SDM), serta memperburuk kesehatan dan pendidikan pada suatu negara. Karenanya, usaha penanggulangan kemiskinan harus dilaksanakan secara terpadu dan benar.

Indonesia merupakan Negara Muslim terbesar di dunia, terlihat dari 85,1\% penduduk Indonesia beragama muslim. Menurut umat muslim, cara untuk mengatasi kemiskinan adalah dengan Zakat, Infaq, Shadaqah, dan Wakaf (ZIZWAF). Ditambah apabila masyarakat Indonesia mempunyai kesadaran untuk membayar zakat serta infak dan wakaf, maka dipastikan dana ZIZWAF yang terkumpul pasti lebih besar. Zakat sendiri merupakan rukun Islam ketiga yang wajib untuk ditunaikan bagi umat muslim.

Selain melalui ZIZWAF, usaha untuk menanggulangi dan mengurangi

\footnotetext{
${ }^{1}$ Jurnal ini merupakan bagian dari skripsi Hamidatul Husnah, NIM: 04151 1433082, yang diuji pada tanggal 25 Juni 2019.
} 
Ramadhan, et al/Jurnal Ekonomi Syariah Teori dan Terapan Vol. 6 No. 8 Agustus 2019: 1637-1643; HUBUNGAN DANA PENANGGULANGAN KEMISKINAN PEMERINTAH DAN ZISWAF TERHADAP JUMLAH PENDUDUK MISKIN

kemiskinan di Indonesia selalu menjadi program prioritas pada setiap era kepresidenan di Indonesia. Biro Analisa Anggaran dan Pelakasaan APBN (2014) menjelaskan bahwa terdapat perbedaan pada program pengentasan di setiap era presiden, contohnya pada Presiden Soeharto yang menjadi program unggulan merupakan inpres desa tertinggal. Masa presiden B.J Habibie, mempunyai program unggulan yaitu Jaring Pengaman Sosial, ketika Presiden Abdurrahman Wahid, programnya adalah pengembangan budaya usaha bagi masyarakat miskin. Program tarif listrik rendah bagi rumah tangga miskin serta subsidi bunga murah untuk usaha mikro pada masa Presiden Megawati, lalu pada masa Presiden Susilo Bambang Yudhyono adalah dengan klaster program penanggulangan kemiskinan, dan yang terakhir pada masa Presiden Joko Widodo mempunyai program kartu Indonesia sejahtera dan program pangan.

Pangan merupakan kebutuhan utama manusia. Suryana dalam Wardini (2018) menjelaskan bahwa ketersediaan pangan merupakan hal terpenting terutama dalam kelangsungan penyediannya dari dalam negeri yang dapat ditempuh dengan meningkatkan kemampuan untuk memproduksi pangan secara mandiri. Indonesia merupakan negara agraris, yang disayangkan adalah tingkat kesejehateraan petani masih kurang, karenanya pemerintahmengucurkan dana anggaran sebesar 52,2 triliun rupiah untuk subsidi pangan(kompas.com).Dengan dana sebesar itu diharapkan para kesejahteraan petani di Indonesia meningkat serta membuka lapangan kerja baru di desa sehingga tingkat pengangguran dan kemiskinan di Indonesia berkurang.

Oleh karena itu pengawasan dan sosialisasi pemerintah tentang penanggulangan kemiskinan dan ZIZWAF perlu dilakukan agar dapat mengurangi jumlah penduduk miskin di Indonesia.Daripermasalahan yang telah diuraikan diatas, maka peneliti tertarik untuk melakukan penelitian dengan judul "Hubungan Dana Penanggulangan Kemiskinan Pemerintah dan ZISWAF Terhadap Jumlah Penduduk Miskin".

\section{LANDASAN TEORI}

Kemiskinan memiliki pemahaman yang beragam, sehingga tidak cukup untuk menggambarkan kemiskinan di bidang-bidang ilmu tertentu. Menurut Bappenas (2004), kemiskinan adalah kondisi seseorang atau kelompok yang tidak dapat memenuhi kebutuhan dasar dan mengembangkan kehidupan yang bermartabat. Bank Dunia dalam Ruslan (2015) mendefinisikan kemiskinan adalah "pronounced deprivation in well-being", yang mempunyai arti bahwa kemiskinan adalah kehilangan kesejahteraan.

Menurut Qardhawi (1996: 184), orang miskin adalah orang yang dapat memenuhi setengah atau lebih dari kebutuhan mereka tetapi tidak dapat 
Ramadhan, et al/Jurnal Ekonomi Syariah Teori dan Terapan Vol. 6 No. 8 Agustus 2019: 1637-1643; HUBUNGAN DANA PENANGGULANGAN KEMISKINAN PEMERINTAH DAN ZISWAF TERHADAP JUMLAH PENDUDUK MISKIN

sepenuhnya memenuhi kebutuhan mereka. Secara umum dapat diartikan bahwa orang miskin adalah orang miskin yang membutuhkan bantuan dari orang lain.

Menurut Huda dkk (2012:88) zakat secara bahasa merupakan penyucian serta pertumbuhan. Qardhawi (1996:34) mendefinisikan zakat menurut bahasa berasal dari kata zaka yang mempunyai arti berkah, tumbuh, bersih, dan baik.

Zakat secara syara merupakan penyerahan pemilikan tertentu kepada orang yang berhak menerimanya dengan syarat-syarat tertentu. Perintah Allah bagi umat Islam mendirikan sholat dan membayar zakat dapat ditemukan di dalam QS. Al Baqarah ayat 43 yang berbunyi:

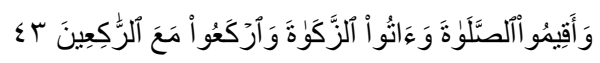

Wa 'Aqīmū Aş-Şalāata Wa 'Ātū Az-Zakāata Wa Arka ū Ma`a Ar-Rāki'īna

Dan dirikanlah shalat, tunaikanlah zakat dan ruku'lah beserta orang-orang yang rukU'. (QS. Al-Baqarah:43)

Menurut Latifa (2013) infak berasal dari kata anfaqa yang mempunyai arti mengeluarkan harta untuk kepentingan sesuatu. Undang-Undang Republik Indonesia Nomor 23 tahun 2011 tentang Pengelolaan Zakat, Bab I pasal 1 ayat 3 menyatakan bahwa infak adalah harta yang dikeluarkan oleh seseorang atau badan usaha diluar zakat untuk kemaslahatan umum. Allah telah berfirman dalam Al-Qur'an surat AlBaqarah ayat 195, yang berbunyi:

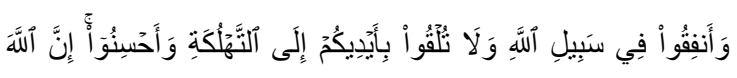
1900

Wa 'Anfiqū Fi Sabīi Allāhi Wa Lā Tulqū Bi'ayalikum 'llá At-Tahlukati ¿ Wa 'Aĥsinū '̊ 'Inna Allāha Yuhibbu AlMuĥsinīna

Dan belanjakanlah (harta bendamu) di jalan Allah, dan janganlah kamu menjatuhkan dirimu sendiri ke dalam kebinasaan, dan berbuat baiklah, karena sesungguhnya Allah menyukai orang-orang yang berbuat baik. (QS. AlBaqarah:195).

Sedekah menurut bahasa dapat diartikan juga dengan zakat wajib. Menurut Qardhawi (1994:16) sedekah itu zakat dan zakat itu adalah sedekah. Sesuai dengan firman Allah dalam AlQur'an surat At-Taubah ayat 58, yaitu:

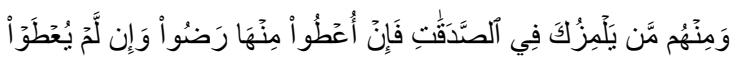

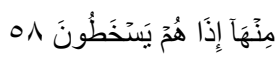

Wa Minhum Man Yalmizuka Fi Aş-Şadaqāti Fa'in 'Ưțū Minhā Rađū Wa 'In Lam Yư țaw Minhā 'Idhā Hum Yaskhațūna Dan di antara mereka ada orang yang mencelamu tentang (distribusi) zakat; jika mereka diberi sebahagian dari padanya, mereka bersenang hati, dan jika mereka tidak diberi sebahagian dari padanya, dengan serta merta mereka menjadi marah. (QS. At-Taubah:58)

Sedekah menurut terminologi Syariah memiliki konsep yang sama dengan infak yaitu mengeluarkan sebagian harta untuk kepentingan yang diperintahkan oleh Islam (Hafidhuddin, 2002:14-15). 
Ramadhan, et al/Jurnal Ekonomi Syariah Teori dan Terapan Vol. 6 No. 8 Agustus 2019: 1637-1643; HUBUNGAN DANA PENANGGULANGAN KEMISKINAN PEMERINTAH DAN ZISWAF TERHADAP JUMLAH PENDUDUK MISKIN

Menurut Huda dan Heykal (2010: 308) wakaf secara etimologi berasal dari kata waqafa-yaqifu-waqfan, yang berarti tegak, menahan. Menurut Mahzab Hanafi, wakaf memiliki arti yaitu menahan benda yang status kepemilikannya tetap milik wakif (orang yang berwakaf) dan yang disedekahkan merupakan manfaat dari harta benda wakaf.

Program penanggulangan kemiskinan adalah program pemerintah Indonesia yang ditujukan untuk mengurangi kemiskinan di Indonesia. Program ini sudah ada sejak 1998. Program ini dibentuk karena pertumbuhan orang miskin di Indonesia, yang relatif tinggi akibat krisis 1998. Dengan program ini, kemiskinan di Indonesia dapat menurun pada tahun 2011 sekitar 12,49\%. (tnp2k.go.id).

\section{METODE PENELITIAN}

\section{Pendekatan Penelitian}

Pendekatan penelitian skripsi ini menggunakan pendekatan kuantitatif dengan menggunakan pendekatan korelasi Spearman. Penelitian dengan menggunakan pendekatan kuantitatif adalah penelitian yang menitikberatkan pada pengujian hipotesis, data yang digunakan harus terukur dan akan menghasilkan kesimpulan yang dapat digeneralisasikan. Penelitian ini akan membuktikan hubungan dana penanggulangan kemiskinan dan ZISWAF terhadap kemiskinan di Indonesia

\section{Definisi Operasional}

1. Dana Penanggulangan Kemiskinan $\left(X_{1}\right)$
Dana penanggulangan kemiskinan merupakan dana yang dikeluarkan oleh pemerintah untuk mengurangi tingkat kemiskinan di Indonesia.

2. Dana ZISWAF (X2)

Zakat merupakan penyerahan pemilikan kepada orang yang berhak menerimanya, infak merupakan harta yang dikeluarkan untuk kepentingan umum, sedekah merupakan harta ataupun non harta yang dikeluarkan untuk kepentingan umum sedangkan wakaf adalah menahan benda dan disedekahkan untuk yang membutuhkan.

3. Kemiskinan (Y)

Kemiskinan merupakan ketidakmampuan seseorang untuk memenuhi kebutuhan dasar. Tingkat kemiskinan diukur melalui presentase penduduk miskin di Indonesia.

\section{Jenis dan Sumber Data}

Jenis data yang digunakan dalam penelitian ini adalah data sekunder.Data sekunder adalah data yang diperoleh oleh suatu organisasi atau perusahaan dalam bentuk yang sudah jadi berupa publikasi (Sugiyono, 2011 :79). Sumber data berasal dari website pemerintah dan baznas. Periode yang diambil dalam penelitian ini adalah Januari 2013September 2017.

\section{Teknik Analisis}

Uji korelasi Spearman merupakan sebuah metode yang digunakan untuk mengetahui apakah terdapat sebuah hubungan antara variabel dan berapa 
Ramadhan, et al/Jurnal Ekonomi Syariah Teori dan Terapan Vol. 6 No. 8 Agustus 2019: 1637-1643; HUBUNGAN DANA PENANGGULANGAN KEMISKINAN PEMERINTAH DAN ZISWAF TERHADAP JUMLAH PENDUDUK MISKIN

besar pengaruh antar variabel tersebut. Menurut Sugiyono (2011:282) "korelasi spearman rank digunakan untuk mencari ataupun untuk menguji signifikansi hipotesis asosiatif bila masing-masing variabel yang dihubungkan berbentuk ordinal, dan sumber data antar variable tidak harus sama".

\section{Hasil dan Pembahasan}

Analisis Korelasi Spearman

Tabel 1.

Hasil Uji Spearman

\begin{tabular}{|c|c|c|c|c|}
\hline & & & $\begin{array}{l}\text { Dana Pengentasan } \\
\text { Kemiskinan (dalam } \\
\text { triliun rupiah) }\end{array}$ & $\begin{array}{l}\text { Presentase } \\
\text { Penduduk } \\
\text { Miskin (\%) }\end{array}$ \\
\hline \multirow[t]{2}{*}{$\begin{array}{l}\text { Spearman's } \\
\text { rho }\end{array}$} & $\begin{array}{l}\text { Dana Pengentasan } \\
\text { Kemiskinan (dalam } \\
\text { triliun rupiah) }\end{array}$ & $\begin{array}{l}\text { Correlation } \\
\text { Coefficient } \\
\text { Sig. (2-tailed) } \\
\mathrm{N}\end{array}$ & $\begin{array}{r}1,000 \\
. \\
57 \\
\end{array}$ & $\begin{array}{r}-, 940^{* *} \\
\\
, 000 \\
57 \\
\end{array}$ \\
\hline & $\begin{array}{l}\text { Presentase Penduduk } \\
\text { Miskin (\%) }\end{array}$ & $\begin{array}{l}\text { Correlation } \\
\text { Coefficient } \\
\text { Sig. (2-tailed) } \\
\mathrm{N}\end{array}$ & $\begin{array}{r}-, 940^{* *} \\
.000 \\
57 \\
\end{array}$ & $\begin{array}{r}1,000 \\
57 \\
5\end{array}$ \\
\hline
\end{tabular}

Berdasarkan hasil uji korelasi pada tabel di atas, dapat dilihat bahwa dana penanggulangan kemiskinan dan persentase penduduk miskin menunujukkan bahwa koefisien korelasi adalah 0,940. Sugiyono (2011) menyatakan bahwa ketika korelasi berada pada rentang 0,800 hingga 1,00 maka korelasi antar kedua variabel sangat tinggi.
Kemudian, koefisien relasi menunjukkan nilai yang negatif. Hal ini menunjukkan bahwa hubungan antar kedua variabel bersifat negatif, ketika terjadi kenaikan pada dana penangulanggan kemiskinan maka akan terjadi penurunan pada persentase penduduk miskin. Sebaliknya, jika terjadi pernurunan pada dana penangulanggan kemiskinan maka terdapat kenaikan pada persentase penduduk miskin.

Tabel 2.

Hasil Uji Spearman

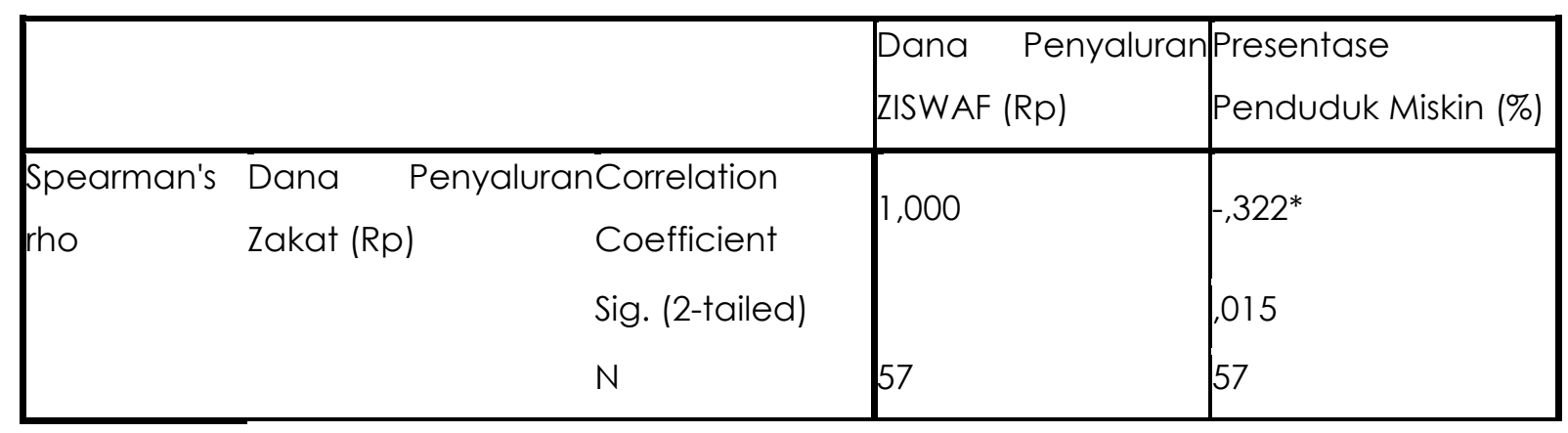


Ramadhan, et al/Jurnal Ekonomi Syariah Teori dan Terapan Vol. 6 No. 8 Agustus 2019: 1637-1643; HUBUNGAN DANA PENANGGULANGAN KEMISKINAN PEMERINTAH DAN ZISWAF TERHADAP JUMLAH PENDUDUK MISKIN

\begin{tabular}{|c|c|c|c|}
\hline $\begin{array}{l}\text { Presentase } \\
\text { Penduduk Miskin (\%) }\end{array}$ & $\begin{array}{l}\text { Correlation } \\
\text { Coefficient } \\
\text { Sig. (2-tailed) } \\
\mathrm{N}\end{array}$ & $\mid \begin{array}{l}-322 * \\
0,15 \\
57\end{array}$ & $\mid \begin{array}{l}-1,000 \\
57\end{array}$ \\
\hline $\begin{array}{l}\text { Berdasarkan hasil uji korelc } \\
\text { tabel di atas, dapat dilihat bahy } \\
\text { ZISWAF dan persentase pendudu }\end{array}$ & $\begin{array}{l}\text { asi pada } \\
\text { wa dana } \\
\text { Uk miskin }\end{array}$ & $\begin{array}{l}\text { 1. Pemerintah } \\
\text { mempertah } \\
\text { dana pen } \\
\text { agar jumlah }\end{array}$ & $\begin{array}{l}\text { diharapkan untuk } \\
\text { an serta meningkatkan } \\
\text { gulangan kemiskinan } \\
\text { iduduk miskin menurun. }\end{array}$ \\
\hline
\end{tabular}

adalah 0,322. Sugiyono (2011)

2. Pemerintah diharapkan membantu menyatakan bahwa ketika korelasi berada pada rentang 0,200 hingga 0,399 maka korelasi antar kedua variabel rendah. Kemudian, koefisien relasi menunjukkan nilai yang negatif.

Hal ini menunjukkan bahwa hubungan antar kedua variabel bersifat negatif, ketika terjadi kenaikan pada dana ZISWAF maka akan terjadi penurunan pada persentase penduduk miskin. Sebaliknya, jika terjadi pernurunan pada dana ZISWAF maka terdapat kenaikan pada persentase penduduk miskin.

\section{v. SIMPULAN}

Berdasarkan pada analisis dan pembahasan yang dijelaskan maka didapatkan kesimpulan bahwa dana penanggulangan kemiskinan mempunyai hubungan erat dan negatif pada tingkat kemiskinan dan dana ZISWAF mempunyai hubungan yang tidak erat dan negatif pada tingkat kemiskinan.

Berdasarkan kesimpulan diatas, saran yang disampaikan dalam penelitian ini adalah: ZISWAF serta mendukung programprogram yang diciptakan BAZNAS sehingga semakin mudah untuk proses pendistribusian dana ZISWAF dan mewajibkan masyarakat untuk melakukan zakat maal, pertanian serta perdagangan melalui undang-undang.

3. BAZNAS diharapkan dapat meningkatkan kinerjanya, dengan cara meningkatkan jumlah penghimpunan dan penyaluran dana ZISWAF yang amanah, profesional, akuntabel serta terintegrasi.

4. Bagi Peneliti selanjutnya, disarankan untuk menambah variabel seperti ziswaf seluruh LAZ dan BAS tidak hanya melalui BAZNAS saja, subyek penelitian dan periode penelitian untuk mendapatkan hasil penelitian yang lebih baik.

\section{DAFTAR PUSTAKA}

Al-Qur'an dan Terjemahannya. 2004. AlJumānatul 'Āli: Al-Qur'an dan Terjemahannya. Departemen Agama Republik Indonesia. Bandung: J-ART. 
Ramadhan, et al/Jurnal Ekonomi Syariah Teori dan Terapan Vol. 6 No. 8 Agustus 2019: 1637-1643; HUBUNGAN DANA PENANGGULANGAN KEMISKINAN PEMERINTAH DAN ZISWAF TERHADAP JUMLAH PENDUDUK MISKIN

Badan Perencanaan Pembangunan Nasional (BAPPENAS). 2010. RPJMN Tahun 2010-2014. Jakarta: Bappenas

Hafidhuddin, Diddn. 2002. Zakat dalam Perekonomian Modern. Jakarta: Gema Insani

Huda, Nurul, dkk. 2008. Ekonomi Makro Islam: Pendekatan Teoritis. Jakarta: Kencana Prenada Media Grup.

Huda, N. Heykal, M. 2010. Lembaga Keuangan Islam. Jakarta: Prenamedia Group.

Latifah, Anna Ayyun. 2013. Pengaruh Promosi Terhadap Loyalitas Donatur Untuk Menyalurkan Zakat Infaq Shadaqah (ZIS) Pada Dompet Dhuafa Jawa Timur. Surabaya. Skripsi tidak diterbitkan. Universitas Airlangga Surabaya.

Qardhawi, Yusuf. 1996. Hukum Zakat (Penerjemah :Harun Salman, Hafidhuddin Didin dan Hasanuddin). Bandung. Mizan dan PT Pustaka Litera AntarNusa. Cetakan ke-5.
Ruslan, Kadir. 2015. Jumlah Si Miskin (5): Garis Kemiskinan Bank Dunia. (Online) (https://kompasiana.com diakses 4 Maret 2018)

Ryandono, Muhammad Nafik Hadi. 2008. Ekonomi ZISWAQ (Zakat, Infaq, Shadaqah dan Waqaf). Surabaya. IFDI dan Cenforis.

Sadono, Sukirno. Makroekonomi. Teori Pengantar. Edisi Ketiga. Jakarta. PT. Grasindo Persada.

Santoso, Singgih. 2012. Analisis SPSS pada Statistik Parametrik. Jakarta. PT. Elex Media Komputindo.

Sugiyono. 2011. Metode Penelitian Kuantitatif, Kualitatif dan R\&D.Bandung. CV Alfabeta.

Wardani, Susma Anik. 2018. Determinan Ketahanan Pangan dan Gizi Rumah Tangga Petani Indonesia di Kawasan Pedesaan. Surabaya: Universitas Airlangga

www.bps.go.id

www.pusat.baznas.go.id

tnp2k.go.id 